Copyright (c) 2016 Linhas Críticas

(c) ${ }_{\mathrm{EY}}$

Este trabalho está licenciado sob uma licença Creative Commons Attribution 4.0 International License. Fonte:

https://periodicos.unb.br/index.php/linhascriticas/article/view/3202. Acesso em: 15 fev. 2022.

Referência

MOREIRA, Ana Maria de Albuquerque et al. A vida cotidiana e a docência universitária. Linhas Críticas, Brasília, v. 10, n. 19, p. 203-216, 2012. DOI: 10.26512/lc.v10i19.3202. Disponível em: https://periodicos.unb.br/index.php/linhascriticas/article/view/3202. Acesso em: 15 fev. 2022. 


\title{
A vida cotidiana e a docência universitária
}

\section{Everyday life and university teaching}

\author{
Ana Maria de Albuquerque Moreira * \\ Antônio Fávero Sobrinho** \\ Ilma Passos Alencastro Veiga *** \\ José Vieira de Sousa **** \\ Livia Freilas Fonseca Borges ***** \\ Lúcia Maria Gonçalves de Resende ****** \\ Maria Eveline Pinheiro ******
}

\begin{abstract}
Resumo
O presente artigo é parte integrante do trabalho de um grupo de pesquisadores voltados para a investigação sobre a docência universitária. O cotidiano representa uma das dimensōes de análise da referida investigação. As reflexões teóricas produzidas a partir de autores referenciais sobre a temática em estudo revelam um novo cenário de pesquisa no campo educacional, em especial da docência universitária, recolocando o cotidiano no centro das discussōes emergentes. Neste sentido, busea-se estabelecer as relaçōes entre os conceitos de 'vida cotidiana' desenvolvidos por três autores diferentes: Heller, Lefebvre e Certeau.
\end{abstract}

Palavras-chave: Vida cotidiana. Docência universitária. Educaçāo superior.

\begin{abstract}
This article is part of the work of a research group interested in investigating university teaching. The everyday represents one of the analysis dimensions of this investigation. The theoretical reflections produced from referential authors about the thematic under study expose a new research setting in the educational area, especially in university teaching, restoring the everyday in the center of the emerging debate. In this sense, it intends to establish the relations among 'everyday life' concepts developed by three different authors: Heller, Lefebvre and Certeau.

Keywords: Everyday life. University teaching. Higher education.

* Mestre em Educaçāo pela UnB. Professora do IESB. E-mail: ana_moreira@hotmail.com ** Doutorando em História pela UnB. Prof. Assistente da FE/UnB. E-mail: afavero@unb.br *** Doutora em Educação. Pesquisadora Sênior da FE/UnB. E-mail: ipaveiga@ (erra.com.br **** Doutor em Sociologia pela UnB. Prof. Adjunto da FE/UnB. E-mail: sovieira@fe.unb.br ***** Doutora em Sociologia pela UnB. Profa. Adjunta da FE/UnB.E-mail: liviaffb@terra.com.br ***** Doutora em Educação pela Unesp. Profa. Adjunta da FE/UnB.E-mail: antorf@zaz.com.br ****** Mestre em Educação pela UnB. Professora do IESB. E-mail: mariaeveline@hotmail.com
\end{abstract}




\section{Résumé}

\section{La vie quotidienne et le magistère universitaire}

Cet article fait partie du travail d'un groupe de recherche dont l'intérêt porte sur la recherche sur l'enseignement universitaire. Le quotidien représente une des catégories d'analyse de la recherche. Les réflections théoriques produites à partir d'auteurs de référence sur la thématique sous étude mettent en évidenee un nouveau quadre dans le champs éducationnel, spécialement l'enseignement universitaire, tout en restaurant le quotidien au centre du débat émergant. Dans ce sens, il prétend établir les relations entre les conceptes de 'vie quotidienne' développés par trois auteurs différents: Heller, Lefebvre et Certeau.

Mots clefs : Vie quotidienne. Enseignement universitaire. Éducation supérieure.

\section{Introdução}

O objetivo deste texto é tecer considerações sobre o significado da vida cotidiana e a docência universitária, procurando compreender sua importância e as implicações dos fatores que programam a vida acadêmica, bem como as possibilidades de resistências para reversão do cotidiano concebido numa perspectiva homogênea, fragmentada e hierarquizada.

Para adentrar a "vida cotidiana", é fundamental a compreensão de conceitos básicos, a fim de desenvolver sua articulação com o locus da docência universitária. Nesse sentido, a compreensão do conceito de vida cotidiana considera a necessidade de este estudo apoiar-se nas contribuições de três autores: Agnes Heller (2000), representante do grupo de pensadores da Escola de Budapeste; Henri Lefebvre (1979), intelectual importante na cultura francesa, chamado por George Gusdorf de "estrela do marxismo"; e Michel de Certeau (2001), historiador francês, conhecido por desenvolver uma teoria das práticas cotidianas sob a perspectiva historiográfica. $O$ intuito é proceder a um mapeamento conceitual da vida cotidiana, pontuando sua discussão no âmbito das relações da docência universitária.

Não se pode negar a importância de investigar a vida cotidiana, visto que as determinações que se constroem em instituições universitárias, como orientações acadêmico-metodológicas, níveis de autonomia social e docente, entre outras, produzem-se e constroem-se do e no cotidiano dos sujeitos. Dessa maneira, tudo o que ocorre e se ressignifica deve vir do cotidiano e retornar a ele para ser confirmado e validado. Para Penin, o conhecimento do cotidiano do espaço educativo aponta para dois aspectos importantes.

Primeiro, porque sendo conhecido é possível conquistá-lo e planejar ações que permitam transformá-lo [...]. Segundo, porque o cotidiano, sendo conhecido, pode fornecer informações a gestões institucionais democráticas que queiram 
tomar medidas adequadas para facilitar o trabalho ao nível do cotidiano das escolas e melhorar a qualidade do ensino aí realizado (1989, p. 161).

Independente de diferentes orientações teórico-metodológicas, os estudos sobre a cotidianidade apontam a complexidade e a contraditoriedade de seu conteúdo. Isto porque sugere, entre outros aspectos, a reflexão sobre a vida dos gestos, das atividades rotineiras e do mundo privado dos sujeitos, em suas ambivalências. Atinge um modo de existência social que flui entre o fictício e o real, o abstratoe o concreto, o homogêneo e o heterogêneo. Constrói sua trajetória em movimentos que refletem o ir e vir entre princípios, significados, crenças, concepções etc.

Entretanto, é relevante não perder de vista a idéia de que assentar a reflexão somente no âmbito da estrutura da vida cotidiana não é suficiente em estudos que se proponham a investigar a cotidianidade da docência universitária. Compartilha-se a idéia de que é preciso construir o cotidiano educativo como categoria de análise, a fim de que seja evitado o empírico por ele mesmo.

Esse pressuposto implica a aceitação, também, da necessidade de questionamentos mais profundos acerca das raízes dos dados coletados no cotidiano universitário, para não cair na reprodução do senso comum, do óbvio. Essa postura possibilita esclarecer relações entre as especificidades da vida cotidiana universitária e sua dinâmica com outras esferas da vida cotidiana em sociedade, em termos mais amplos, e do sistema educativo em particular.

\section{Adentrando no cotidiano concebido por Heller}

A relação dos sujeitos com o cotidiano é direta, propiciando um processo de amadurecimento, que se reproduz diretamente na condição do ser individual e do ser coletivo, como componente de um complexo social. Heller, sustenta que a “... vida cotidiana está no centro do acontecer histórico: é a verdadeira 'essência' da substância social [...]. Toda grande façanha histórica concreta torna-se particular e histórica precisamente graças a seu posterior efeito na cotidianidade" (2000, p. 18).

A autora chama a atenção para a necessidade da crítica sobre a história produzida a partir de uma análise sobre o cotidiano que os homens constroem. Considerando que todo indivíduo possui um cotidiano, é preciso reconhecer que os docentes universitários produzem uma realidade a ser melhor compreendida, tendo-se como referência a função assumida pela universidade no mundo contemporâneo, particularmente no que se refere à realidade brasileira. A autora esclarece, também, que não há nenhum homem que viva somente a sua cotidianidade, visto que todos estão inseridos em um contexto global. "O indivíduo é sempre, simultaneamente, ser particular e ser genérico” (HELLER, 2000, p. 20). 
A vida cotidiana insere-se na história, modifica-se e modifica as relações sociais, e o resultado desse movimento depende, essencialmente, da consciência que os homens possuem de sua "essência"e dos valores presentes ou não em seu desenvolvimento.

A autora não identifica a vida cotidiana como alienação, destacando a unidade entre ser genérico e ser singular, reforçando nesse aspecto a oposição, e não uma diferença. A possibilidade de alienação existe à medida que as pessoas se envolvem nas atividades rotineiras, não permitindo que se reflita sistematicamente sobre as suas próprias condições na sociedade contemporânea. Em decorrência disso, questões importantes e diversas da vida cotidiana fícam encobertas e desprovidas de reflexões mais aprofundadas. É importante aproximar esse entendimento das instituições educativas, que, muitas vezes, são acusadas de levar seus profissionais ao trabalho alienado, e dessa acusação pode-se inferir que a vida cotidiana é atingida por uma das dimensões da alienação, que, segundo Marx, está associada ao caráter da "objetivação". Nessa objetivação, a docência deixa de ser vital, criadora, prazerosa, para se tornar apenas meio de subsistência. "O homem alienado de si mesmo é também o pensador alienado de sua essência [...]" (HELLER, 2000, p. 47).

Nesse contexto, a vida cotidiana passa a ser, também, um espaço de mediocridade, reforçado por alguns valores, como o individualismo, a neutralidade, a competição, e intensificados pela estrutura capitalista de organização social e da organização do trabalho universitário, em particular. Ocorre, assim, uma insatisfação que se manifesta na contestação ou na passividade, que mascara a mediocridade e impede a procura do "ser inteiro". Assim, a cotidianidade será campo de pares contraditórios, como saberes criativos e transformadores, mas também da alienação.

Cabe destacar que a universidade é um locus privilegiado para o enfrentamento do desafio da construção e desenvolvimento de ações pedagógicas significativas que sustentem um projeto social alternativo democrático. $O$ desafio está relacionado à consciência e necessidade de os docentes universitários darem sentido às ações concretas desenvolvidas na sala de aula para a produção de mudanças efetivas no contexto educacional.

Para a autora, a vida cotidiana envolve o homem "inteiro", em todos os seus aspectos e, portanto, em sua individualidade e generalidade. Nem mesmo o fato de que todas as suas capacidades estejam em funcionamento garante a sua intensidade. "O homem da cotidianidade é atuante e fruidor, ativo e receptivo, mas não tem tempo nem possibilidade de se absorver inteiramente em nenhum desses aspectos; por isso, não pode aguçá-los em toda sua intensidade" (HELLER, 2000, p. 17-18). 
É possível identificar nas características da vida cotidiana, definidas por Heller (2000), as relações com o cotidiano da docência universitária:

a) a vida cotidiana é a vida de "todo" homem. lsso significa que ela é vivida por todos, em diferentes aspectos de sua individualidade e personalidade. Nesse sentido, o docente universitário coloca "em funcionamento" todos os seus sentidos, todas as suas capacidades intelectuais, afetivas e psicomotoras;

b) a vida cotidiana é, em grande medida, heterogênea. São partes orgânicas da vida cotidiana: a organização do trabalho e da vida privada, o lazer e o descanso, a atividade social sistematizada, o intercâmbio com a realidade. A vida cotidiana da docência universitária implica reflexão e tomada de decisões sobre a diversidade das ações e atitudes desenvolvidas em sala de aula, propiciando e provocando a construção de saberes. Assim sendo, a heterogeneidade presente em nossa ação docente é vista sob vários aspectos, principalmente no que se refere ao conteúdo e significado das ações pedagógicas;

c) a vida cotidiana é também hierárquica. Essa hierarquia é mutável, alterandose de modo específico em função das diferentes estruturas econômicas e sociais. É, também, condição de organicidade. Nesse sentido, o docente encontra-se imerso em um contexto permeado pela hierarquização espontânea e formal;

d) a vida cotidiana está no centro do acontecer histórico. Em instituiçōes educativas como a universidade, as ações docentes, para se efetivarem, emergem da prática cotidiana, sendo, portanto, necessário conhecê-las, identificando suas características e formas de expressão;

e) a vida cotidiana é a vida do indivíduo, que é, simultaneamente, particular e genérico. $\mathrm{O}$ que caracteriza essa particularidade social são a unicidade e a imprevisibilidade. A dinâmica básica da particularidade humana é a satisfação das necessidades do "eu". O genérico está contido em todo homem, em toda sua atividade que tenha esse caráter, embora seus motivos sejam particulares. Por exemplo, o trabalho docente é carregado de motivações particulares, mas a atividade do trabalho efetivo, socialmente necessário, é sempre uma atividade do gênero humano, bem como os sentimentos e as paixões. O particular não é nem o sentimento nem a paixão, mas sim seu modo de manifestar-se;

f) a vida cotidiana está carregada de alternativas e escolhas. Elas podem ser inteiramente indiferentes do ponto de vista moral, mas podem estar moralmente motivadas. O cotidiano acadêmico está carregado de alternativas e escolhas, de diversas naturezas: pessoais, acadêmicas, administrativas, entre outras;

g) a característica dominante da vida cotidiana é a espontaneidade. Ela é a tendência de toda e qualquer forma de atividade cotidiana, caracterizando tanto motivações particulares, como atividades humanas genéricas. Articuladas ao 
cotidiano da docência universitária, essas motivações estão em permanente mutação, não chegando a tornarem-se típicas, pois não expressam a totalidade do docente;

h) na vida, o homem atua sobre a base da probalidade, da possibilidade. Não é possível, na vida cotidiana, calcular com segurança científica a consequiência possível da ação. Considerando essa característica aplicada à circunstância docente, destacamos a dificuldade de estabelecer, com exatidão, toda a organização prevista na ação educativa, que é marcada pela imprevisibilidade.

Quando falamos em desvelar o cotidiano, nas relações que o docente estabelece, por exemplo, com os saberes profissionais, falamos nos modos como esse docente concebe o ensino, a pesquisa e a extensão. É importante deixar claro, também, que o desvelamento do processo de construção dos saberes profissionais de docentes universitários na vida cotidiana implica um necessário contato permanente e contínuo para apreender toda a complexidade presente na mesma. Investigar processos objetivos e subjetivos da relação dos docentes com sua cotidianidade resulta um processo que demanda tempo e ampliação de pesquisa e, mesmo assim, correndo-se o risco de conclusões e reflexões parciais e/ou reducionistas.

\section{A vida cotidiana postulada por Lefebvre}

Na concepção de Lefebvre, a vida cotidiana é entendida e captada como um nível da realidade social, pois tudo o que é produzido e construído no âmbito das instituições deve procurar sua legitimidade junto ao cotidiano. Assim, "a análise da vida cotidiana envolve concepções e apreciações na escala da experiência social em geral" (1991, p. 28). Para o autor, o cotidiano não é um campo fechado, ligando-se a outros níveis da realidade, não se reduzindo ao limite a que está circunscrito.

De acordo com a matriz teórica em discussão, é no cotidiano que a história se constrói, nos âmbitos econômico, psicológico e sociológico. Nessa lógica, fazem parte da vida cotidiana dos indivíduos os objetos que os rodeiam, os alimentos que consomem, os locais onde moram e trabalham. Enfim, tudo o que acontece com os homens, que está à sua volta e constitui sua vida diária faz parte do seu cotidiano. Em função disso, a vida cotidiana deve merecer um olhar mais apurado de todos aqueles que desejam compreender os processos por meio dos quais se estruturam as relações sociais mais amplas. 
O estudo da vida cotidiana oferece um ponto de encontro para as ciências parcelares a alguma coisa mais. Mostra o lugar dos conflitos entre o racional e o irracional na nossa sociedade e na nossa época. Determina assim o lugar em que se formulam os problemas concretos da produção em sentido amplo: a maneira como é produzida a existência social dos seres humanos, com transições da escassez para a abundância e do precioso para a depreciaçāo (apud PENIN, 1989 , p. 30).

Na vida cotidiana, os homens buscam caminhos e, também, um futuro, não ficando apenas aprisionados em um presente dominado pela lógica instrumental ou em um mundo vivido de forma preconceituosa. Segundo Lefebvre (1991), desvendar a vida cotidiana implica compreender as manipulações que determinam o cotidiano e examinar as representaçōes dos sujeitos nele inseridos.

Para orientar esse exame, o autor apresenta um esquema de análise dos fatores que influenciam a programação da vida cotidiana:

a) homogeneidade: é identificada pela presença de leis e ordens estabelecidas, racionalidade técnica e burocrática, tarefas planejadas linearmente, fragmentações das funções, enciclopedismo e pela concepção da vida acadêmica calcada nos princípios do modelo operacional de universidade, que, na concepção de Chauí (1999), distancia-se do conhecimento e da formação intelectual, para tratar com maior enfoque a organização acadêmica e a eficácia gerencial, que orientam o trabalho docente na busca por índices de produtividade. Os fatores homogeneizantes do cotidiano são altamente normatizadores e centralizadores, por serem definidos de maneira vertical;

b) fragmentação: esse fator reflete a divisão do trabalho, provocando múltiplas dicotomias, como: público/privado, concebido/executado, natural/ técnico, teórico/prático, sujeito/objeto. Essas dicotomias provocam cisões entre os que pensam e os que executam a docência universitária, fortalecendo o individualismo e o isolamento;

c) hierarquização: esse fator programa o cotidiano, de forma a estabelecer a hierarquia entre os saberes, definindo e priorizando aqueles que são considerados valiosos e de maior prestígio. A programação mediante fatores de hierarquização é reforçada pelo grau de participação no poder e nas tomadas de decisões.

No estudo da ação docente e do cotidiano dos espaços acadêmicos, é possível identificar essas forças atuando na organização e estruturação do trabalho a ser realizado. Com freqüência, a ação docente no cotidiano da sala de aula cumpre e reforça as determinações burocráticas e técnicas, homogeneizando o diferente, fragmentando o contínuo e direcionado pela unidade de pensamento e ação, bem como hierarquizando a convergência para a igualdade. 
Além de organizar o quadro de fatores que intervêm no cotidiano, Lefebvre (1991) apresenta movimentos que se constituem como fatores de oposição ou movimentos de resistência, em contraposição à programação da vida cotidiana:

a) as diferenças contra a homogeneidade são definidas socialmente nas relações sociais, não se isolando. Tomam lugar no conjunto dessas relações e podem ser identificadas pelas diversidades;

b) a unidade contra a fragmentação caracteriza-se pela unicidade de pensamento e ação, permeada pela intencionalidade;

c) a igualdade contra a hierarquia pode identificar-se pela tentativa de fortalecer o social quanto ao nível mediador entre o econômico e o político, considerados fatores de desigualdade. Nesse sentido, vale salientar a importância dos processos participativos de tomada de decisões e a busca de fins determinados de forma democrática.

A compreensão da vida cotidiana nas universidades permite um entendimento mais preciso sobre como são formulados processos, procedimentos e ações realizadas em função de uma programação acadêmica e que vão influenciar na constituição dos saberes docentes. Isso, pela ótica de Lefebvre (1991), significa analisar as implicações da vida cotidiana nas universidades e na estruturação da docência. Tais implicações podem ser melhor diferenciadas utilizando-se como referencial alguns aspectos presentes na vida cotidiana do docente: a organização da produção de ensino, pesquisa e extensão; as relações com os alunos; as condições de trabalho e, por fim, as expectativas profissionais e na carreira docente.

Assim, os fatores de homogeneidade, fragmentação e hierarquização do cotidiano discutidos anteriormente estão presentes na organização do trabalho do docente universitário: a divisão do trabalho; os espaços da especialização, gerando guetos; as burocracias e fidelidades burocráticas; os campos epistemológicos e os recortes operados para e no saber (PENIN, 1989).

A aplicação do conceito de vida cotidiana à reflexão da docência universitária leva ao entendimento de que as deliberações oficiais tomadas em instâncias hierarquicamente superiores derivam e precisam buscar sua validade nas práticas vivenciadas no cotidiano das universidades, encaradas estas como microssistemas. Nesse sentido, medidas como, por exemplo, a institucionalização da gratificação de estímulo à docência (GED), elaboração de planejamentos educacionais, definição de currículo, adoção de propostas pedagógicas, a avaliação externa de produtos e legislações educacionais atestam a existência de uma via de mão dupla nesse processo.

Por fim, pode-se compreender que os homens procuram construire fortalecer uma individualidade, visando superar os limites de práxis repetitivas. Nessa 
lógica, os indivíduos buscam instalar uma práxis libertadora e inventiva, considerando que nada é isolado. "Isolar um fato, um fenômeno, e depois conservá-lo pelo entendimento nesse isolamento, é privá-lo de sentido, de explicação, de conteúdo. É imobilizá-lo artificialmente, matá-lo" (LEFEBVRE, 1991, p. 238).

\section{A vida cotidiana e as revelações de Certeau}

Ao longo da modemidade ocidental, o docente universitário, para além de suas versōes identitárias - sujeito metafísico, sujeito da razão, sujeito da ciência -, tomou-se um verdadeiro "deus de outrora" (CERTEAU, 2001), pois, como um "homem de cultura esclarecida", passou a ser visto como um sujeito estritamente pensante, a-histórico, apartado do mundo, distante da realidade e que vive no mundo das idéias, das teorias e da pura abstração.

Nos últimos anos, essa visão essencialista do sujeito vem sofrendo fortes críticas por parte das mais variadas correntes do pensamento que procuram compreender o sujeito pela perspectiva histórico-cultural. Nesse aspecto, a corrente historiográfica denominada Nova História apresenta contribuições relevantes para se compreender e situar o sujeito histórico na dimensão sóciocultural do cotidiano.

Após um período de rejeição, por ser considerada trivial, a história do cotidiano abre possibilidades de recuperação de outras experiências que nela estão presentes. $O$ cotidiano não é um terreno relegado apenas aos hábitos e rotinas obscuras. Ele corresponde a uma dimensão histórica que revela todo um universo de tensões e movimentos em que estão presentes uma multiplicidade de formas peculiares de resistência/luta, integração/diferenciação, permanência/ transformação, nas quais a mudança não está excluída, mas sim vivenciada de diferentes formas.

A incorporação da dimensão do cotidiano permite restaurar as tramas e experiências que estão encobertas, desvelar as ambigüidades e a pluralidade de possíveis vivências e interpretações, desfiar a teia de relaçōes cotidianas e suas diferentes dimensões de experiência, fugindo dos dualismos e polaridades, bem como questionando as dicotomias.

Sob a perspectiva histórica, a abordagem do cotidiano contribui para trazer à cena da pesquisa uma pluralidade de vivências, mostrando que coexistem tanto o tempo imutável das práticas e das experiências, como as ações dinâmicas e criativas da prática docente. Nessa perspectiva histórica, o cotidiano procura ir além daquilo que escapa aos sujeitos individuais da história ao voltar-se para os pensamentos e gestos coletivos e para novas questões em que estão presentes as diferenças, as múltiplas individualidades, os vários procedimentos diários 
nas "artes de fazer", as inúmeras maneiras de negar a ordem estabelecida e o estatuto da lei, entre outras.

A apropriação dessa concepção de cotidiano pela educação permite que se compreenda que a epistemologia da docência universitária não se dá no vazio, mas que é um constructo histórico, no qual está presente uma teia de relações, práticas, experiências e trocas cotidianas.

Ao abordar a formação do professor, Tardif chama a atenção para o fato de que a epistemologia da prática docente, por ser um fenômeno temporal, está relacionada diretamente ao cotidiano e à rotina:

... agir no tempo, como o tempo: a ação se insere, portanto, na duraçāo. Ora, um dos problemas capitais da atividade humana é justamente o de captar como uma açāo pode manter-se através do tempo, tanto subjetivamente, já que, em tese e fato, é o mesmo ator que age, quanto objetivamente, já que a ação se repete de uma forma relativamente estável e que todas as lições se assemelham umas às outras: dia após dia, é sempre "o mesmo" professor que entra na sala de aula; dia após dia, ele dá a "mesma" lição diante dos "mesmos" alunos (2002, p. 215).

Dessa forma, as rotinas, como dimensão sociotemporal do ensino, são parte integrante da atividade profissional, na medida em que possibilitam revelar as "maneiras de ser" do professor, seu "estilo", sua "personalidade profissional".

A valorização do sujeito histórico como um ator comum se faz presente no cenário da teoria do cotidiano de Certeau (2001). Desta, depreende-se que o docente universitário não é apenas um sujeito pensante, estando a prática discursiva acima de tudo. Sob a perspectiva do cotidiano, ele é também um "homem ordinário", pois em seu fazer está presente um conjunto de práticas acadêmicas não-discursivas que correspondem a um repertório de várias maneiras da arte de dizer, fazer e pensar.

Esse repertórioé inventado e reinventado cotidianamente pelo sujeito docente em um espaço de práticas, a universidade, locus onde desenvolve as suas operações, que são constituídas de processos de disputa, negociações, conflitos e concessões que demarcam relações de poder entre os diferentes sujeitos que compõem o cenário acadêmico. Dessa forma, a universidade, constitui-se em um espaço no qual se realiza um conjunto de "... operações quase microbianas que proliferam no seio das estruturas tenocráticas e alteram o seu funcionamento por uma multiplicidade de 'táticas' articuladas sobre os detalhes do cotidiano" (CERTEAU, 2001, p. 41). 
O cotidiano universitário é, também, tempo e espaço de práticas da arte de dizer e de pensar sobre as artes do fazer (ensinar, aprender, pesquisar, avaliar). Por essa razão, investigar o cotidiano da docência universitária é mais que decifrar as diferentes tarefas que compõem um quadro de ações comuns que vão se estabelecendo na prática pedagógica do dia-a-dia. É, ainda, buscar a compreensão de como se dão as relações entre teoria e prática e como a teoria vai sendo construída a partir dessa mesma prática que se quer pesquisar, como um repertório de conhecimentos e "operaçōes" didáticas, depreendido de uma dada rotina de trabalho.

Os repertórios das diversas práticas do cotidiano docente universitário são passíveis de uma teorização que se produz a partir de idéias que vão sendo elaboradas no campo da memória e das lembranças, descritas no tempo presente, cunhadas por meio de uma representação das vivências, cujas imagens são transportadas de um outro tempo e espaço para o contexto atual.

\section{Aspectos cotidianos da docência universitária: considerações gerais}

A reflexão proposta neste trabalho permite sinalizar para alguns aspectos, ainda que estes sejam marcados pela provisoriedade implícita a todo trabalho acadêmico.

- O primeiro deles é que não se pode negar a importância de se investigar a vida cotidiana, visto que as determinações que se constroem em instituiçōes universitárias, como orientações acadêmico-metodológicas, níveis de autonomia social e docente, entre outras, constitui-se no âmbito do cotidiano e a partir dele. Dessa maneira, tudo que ocorre e se ressignifica deve vir do cotidiano e retornar a ele para ser confirmado e validado. Nesse sentido, o cotidiano é visto como espaço e tempo de embate entre o concebido e o vivido.

- Um segundo aspecto a destacar diz respeito à relevância de não se perder de vista a idéia de que assentar a reflexão somente no âmbito da estrutura da vida cotidiana não é suficiente em estudos que se proponham a investigar a docência universitária. Compartilha-se da idéia de que é preciso construir o cotidiano educativo como categoria de análise, a fim de que seja evitado o empírico por ele mesmo.

- As análises revelam um potencial crítico e inventivo de grupos docentes, sujeitos coletivos e individuais que se relacionam, refletem e dicotomizam as dimensões micro e macro. O desafio para a docência universitária reside em conceber referenciais teórico-metodológicos que promovam o diálogo 
epistemológico entre o micro e o macro que possam dar conta das várias modalidades apresentadas pela vida social nos dias de hoje. Esse aspecto implica a aceitação da necessidade de questionamentos mais profundos acerca das raízes dos dados coletados no cotidiano universitário, para não cair na mera reprodução do senso comum, do óbvio. Os esforços devem ser feitos, portanto, visando às reflexões sobre e não apenas no cotidiano da docência universitária. Adotar essa postura possibilita esclarecer certas relações entre as especificidades da vida cotidiana universitária e sua dinâmica com outras esferas da vida em sociedade, em termos mais amplos, e do sistema educativo em particular.

- Destacamos como terceiro aspecto a importância da construção da individualidade, uma vez que nela estão presentes contradições entre o universal e o particular. A individualidade é construção interminável, o que significa dizer que o ser singular passa a transcender uma particularidade, chegando à consciência da realidade. Da mesma forma, a dialética entre o genérico e o particular pertence ao processo de tomada de consciência da realidade como uma construção sempre presente no cotidiano e permeada por um complexo relacional de difícil entendimento.

- Um quarto aspecto refere-se ao fato de a universidade constituir um locus privilegiado para o enfrentamento do desafio da construção e desenvolvimento de ações pedagógicas significativas que sustentem um projeto social alternativo democrático. Esse desafio está relacionado à consciência e à necessidade de os docentes universitários darem sentido às ações concretas desenvolvidas na sala de aula para a produção de mudanças efetivas no contexto acadêmicoeducacional.

Os estudos do cotidiano, dada a sua complexidade, requerem uma imersão profunda no campo do real, demandando a necessidade de construir categorias de análise no próprio processo da investigação e aceitação da provisoriedade de conceitos e conhecimentos. Além disso, implicam considerar ritmos desconexos, rotinas ligadas aos hábitos mecânicos e também o tempo criador e inovador.

É nesse sentido que estudos do cotidiano concentram-se em instâncias micro e suas relaçōes com as instâncias macro. No plano micro, há uma localização que permite observação direta e participante, presença dos protagonistas, no caso, docentes e pesquisadores universitários, identificados por suas trajetórias de vida pessoal e profissional, seus arcabouços teóricos e suas práticas, bem como vivências que manifestam experiência total. 


\section{Referências}

ARENDT, Hannah. Entre o passado e o futuro. São Paulo: Perspectiva, 1972.

CERTEAU, Michel de. A invençāo do cotidiano: 1 . artes de fazer. Traduçāo de Ephraim F. Alves. Petrópolis: Vozes, 2001.

CHAUÍ, Marilena. A univcrsidade em ruínas. In: TRINDADE, Hélgio (Org.). Universidade em ruínas: na república dos professores. Petrópolis: Vozes, 1999. p. 211-222.

HELLER, Agnes. O cotidiano e a história. Rio de Janeiro: Paz e Terra, 2000.

KOSIK, Karel. A dialética do concreto. São Paulo: Paz e Terra, I988.

LEFEBVRE, Henri. Critique de la vie quotidienne: Tome II - Fondements d'une sociologie de la quotidienneté, Paris: L'Arche, 1991.

MARX, Karl. Teses sobre Feuerbach. Sāo Paulo: Abril Cultural, 1978 (Coleçāo Os Pensadores).

PENIN, Sônia. Cotidiano e escola: a obra em construção. São Paulo: Cortez, 1989. TARDIF, Maurice. Saberes docentes e formação profissional. Petrópolis: Vozes, 2002. VEIGA, Ilma Passos Alencastro. O cotidiano da aula universitária. In: CASTANHO, Maria Eugênia; CASTANHO, Sérgio. Temas, textos em metodologia do ensino superior. Campinas: Papirus, 2001. p. I43-163.

Recebido: 06.10.2004

Aceilo: 29.11 .2004 


\title{
Consultores ad hoc
}

\author{
Adriana Mabel Fresquet \\ (Universidad Nacional de Cuyo, Mendoza, Argentina) \\ Amaralina Miranda de Souza \\ (Universidade de Brasília -DF) \\ Bráulio Tarcísio Pôrto de Matos \\ (Universidade de Brasília-DF) \\ Eunice Maria Lima Soriano de Alencar \\ (Universidade Católica de Brasília-DF) \\ Gilberto Lacerda Santos \\ (Universidade de Brasilia-DF) \\ Laís Maria Borges de Mourão Sá \\ (Universidade de Brasília-DF) \\ Maria Carmen Villela Rosa Tacca \\ (Universidade de Brasília-DF) \\ Marília Fonseca \\ (Universidade de Brasilia-DF) \\ Messias Costa \\ (Universidade de Brasilia-DF) \\ Regina Maria Pavanello \\ (Universidade Estadual de Maringá - PR) \\ Rita Carolina Vereza Bruzzi \\ (Universidade de Brasilia-DF) \\ Solange Muglia Wechsler \\ (Pontificia Universidade Católica de Campinas - SP) \\ Walter Omar Kohan \\ (Universidade Estadual do Rio de Janeiro - RJ)
}

